ArF エキシマレーザーを用いたパルスレーザー堆積法で 成膜した積層透明導電膜の特性*

東村 佳則*1 · 中村 真貴*1 · 奥野 智也*1 · 安倉 秀明*1 鈴木 晶雄*1 ·青木 孝憲*1 松下 辰彦*1 奥田 昌宏*2

\title{
Characteristic of Transparent Conducting ZnO Films with Stacking Structure Prepared by Pulsed Laser Deposition Method using ArF Excimer Laser
}

\author{
Yoshinori HIGASHIMURA*1, Masataka NAKAMURA*1, Tomoya OKUNO*1, Hideaki AGURA*1 \\ Akio SUZUKI*1, Takanori AOKI*1, Tatsuhiko MATSUSHITA*1 and Masahiro OKUDA*2 \\ ${ }^{* 1}$ Department of Electronics, Information and Communication Engineering, Osaka Sangyo University, \\ 3-1-1 Nakagaito, Daito, Osaka 574-8530, Japan \\ *2Okuda Technical Office, 1-2-27 Mozu-Umemachi, Sakai, Osaka, 591-8032, Japan
}

(Received November 7, 2006 Accepted January 13, 2007)

\begin{abstract}
Approximately $300 \mathrm{~nm}$-thick transparent conducting zinc oxide (TCO) films with a stacking structure of ITO (150 nm) and AZO $(150 \mathrm{~nm})$ have been deposited on glass substrates at various temperature. When fabricated with oxygen partial pressure of $0.5 \mathrm{~Pa}$ for ITO layer and $0 \mathrm{~Pa}$ for AZO layer at substrate temperature of $220^{\circ} \mathrm{C}$, the lowest resistivity of $2.04 \times 10^{-4} \Omega \cdot \mathrm{cm}$ and the sheet resistance of $6.83 \Omega / \square$ were obtained for the TCO films. These data were almost the same to that of $300 \mathrm{~nm}$-thick ITO films, which was useful to the reduction of rare indium element.
\end{abstract}

\section{1.はじめに}

近年, プラズマディスプレイ (PDP) や液晶ディスプレ イ (LCD), または電力小売の自由化, $\mathrm{CO}_{2}$ 削減による地球 温暖化防止により太陽電池が急速に普及し透明導電膜の需要 が増加している．これらの透明導電膜のほとんどに希少金属 であるインジウムが使用され，消費量の急激な増加により枯 渴が懸念されている1-3)．そこで最近，インジウムに替わる 材料として, 資源が豊富な酸化亜鉛に注目し, 酸化亜鉛系透 明導電膜の研究が精力的に進められている ${ }^{4-6)}$.

しかしながら，酸化亜鉛を主要材料とする透明導電膜は実 用化される段階までには至っていないのが現状である.

以前にスパッタ法で $\mathrm{ZnO}$ (酸化亜鉛) 膜の上に ITO（酸 化インジウムスズ）膜を積層させた膜の結晶方位についての 報告はされているが7), 今回, 著者らは $\mathrm{ArF}$ エキシマレー ザー（波長193 nm）を用いたPLD (Pulsed Laser Deposition）法で積層膜の成膜を行った.

すなわち, ターゲット材料には現在実用化されている ITO と試作段階にある AZO（アルミニウムをドープした酸 化亜鉛）を用い，積層させることで両者の特徵を生かし，か つインジウムの枯渴問題を視野に入れた省インジウム化を目 的として, ITO + AZO 積層透明導電膜の作製を行った。 そ の結果, 良好な結果が得られたので報告する.

\section{2. 実験方法}

成膜は Table 1 の条件で行った. ITO + AZO 積層透明導

* 平成 18 年 11 月 7 日 第 47 回真空に関する連合講演会で発表 (7P-10)

*1 大阪産業大学工学部電子情報通信工学科（二574-8530 大阪府 大東市中垣内 3-1-1)

*2 奥田技術事務所（干591-8032 大阪府堺市百舌鳥梅町 1-2-27）
Table 1 Preparation conditions of transparent conducting zinc oxide films with stacking structure of ITO + AZO

\begin{tabular}{|c|c|c|}
\hline \multirow{3}{*}{$\begin{array}{c}\text { Laser ArF } \\
\text { Excimer Laser } \\
(\lambda=193 \mathrm{~nm})\end{array}$} & Laser Energy & $60 \mathrm{~mJ}$ \\
\hline & Repetition Frequency & $10 \mathrm{~Hz}$ \\
\hline & Laser Energy Density & $1.2 \mathrm{~J} / \mathrm{cm}^{2}$ \\
\hline \multirow{7}{*}{ Chamber } & Target & $\begin{array}{l}\text { ITO }\left(10 \text { wt. } \% \mathrm{SnO}_{2}\right) \\
\operatorname{AZO}\left(1.5 \text { wt. } \% \mathrm{Al}_{2} \mathrm{O}_{3}\right)\end{array}$ \\
\hline & Substrate & Corning \#7059 \\
\hline & $\begin{array}{l}\text { Target to Substrate } \\
\text { Distance }\end{array}$ & $40 \mathrm{~mm}$ \\
\hline & Substrate Temperature & $150 \sim 240^{\circ} \mathrm{C}$ \\
\hline & Base Pressure & $\sim \times 10^{-4} \mathrm{~Pa}$ \\
\hline & Gas Pressure & $\begin{array}{l}\text { ITO }: 0.5 \mathrm{~Pa}\left(\mathrm{O}_{2}\right) \\
\text { AZO }: 0 \mathrm{~Pa}\end{array}$ \\
\hline & Film Thickness & $\begin{array}{c}300 \mathrm{~nm} \\
\text { ITO : } 150 \mathrm{~nm} \\
\text { AZO : } 150 \mathrm{~nm}\end{array}$ \\
\hline
\end{tabular}

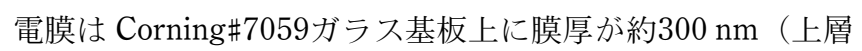
部に ITO : $150 \mathrm{~nm}$, 下層部に AZO : $150 \mathrm{~nm}$ ) 一定となる ように成膜した。実験には $\mathrm{ArF}$ エキシマレーザー（波長193 $\mathrm{nm})$ を用いた。レーザービームは凸レンズで絞り, エネル ギー密度を約 $1.2 \mathrm{~J} / \mathrm{cm}^{2}$ としてターゲットに集光させた。 ターゲットは ITO 10 wt.\% $\left(\operatorname{In}_{2} \mathrm{O}_{3}\right.$ に $\mathrm{SnO}_{2}$ を10 wt.\%添加), AZO 1.5 wt.\% ( $\mathrm{ZnO}$ に $\mathrm{Al}_{2} \mathrm{O}_{3}$ を 1.5 wt.\%添加)を用い, レー ザービームが一個所に集中しないようにするため PC 制御に より回転運動させて成膜を行った. 真空チャンバー内はロー タリーポンプとターボ分子ポンプで $10^{-4} \mathrm{~Pa}$ 台まで真空排気 した後に酸素䨌囲気圧を ITO には $0.5 \mathrm{~Pa}, \mathrm{AZO}$ には $0 \mathrm{~Pa}$ と 


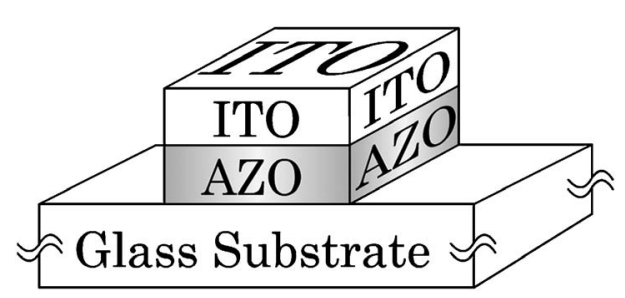

Fig. 1 Illustration of transparent conducting zinc oxide films with stacking structure of ITO + AZO.

した．との他の成膜条件は Table 1 に示す通りである．Fig. 1 に積層させた膜の概略図を示す.

膜の評価は, 膜厚測定には段差式膜厚計，抵抗率などの電 気的特性には van der Pauw 法を用いたホール効果測定装 置, 透過率などの光学的特性には自記分光光度計を用いて行 った。 また表面・断面観察は電界放出型走査電子顕微鏡（以 下 FE-SEM), 結晶構造分析は X 線回折の In-Plane 測定で 行った.

\section{3. 実験結果及び考察}

Fig. 2 に Table 1 の条件下で ArF エキシマレーザー（波 長 $193 \mathrm{~nm}$ ）を用い，チャンバー内の酸素分圧を ITO : 0.5 $\mathrm{Pa}, \mathrm{AZO}: 0 \mathrm{~Pa}$ ，膜厚を ITO : $150 \mathrm{~nm}, \mathrm{AZO}: 150 \mathrm{~nm}$, 基 板温度を $160^{\circ} \mathrm{C} \sim 240^{\circ} \mathrm{C}$ 変化させて成膜した ITO 透明導電 膜と $\mathrm{AZO}$ 透明導電膜の電気的特性（抵抗率 $\rho$, 移動度 $\mu$, キャリア密度 $n$ ）を示す．この図より，ITO は基板温度 180 ${ }^{\circ} \mathrm{C}$ の時に最も抵抗率が減少し, さらに温度を上げると抵抗率 は上昇した。 また，AZO は基板温度を上げることで，抵抗 率が減少する傾向を示した.

Fig. 3 にはITO とAZOの成膜条件に拈いて同じ基板温

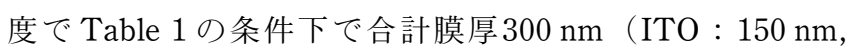
$\mathrm{AZO} ： 150 \mathrm{~nm}$ ) として積層させた膜の電気的特性（抵抗率 $\rho_{\text {(ITO }+\mathrm{AZO})}(\mathrm{ITO}+\mathrm{AZO}$ 積層時の平均的な抵抗率 $)$, 移動度 $\mu_{(\mathrm{ITO}+\mathrm{AZO})}(\mathrm{ITO}+\mathrm{AZO}$ 積層時の平均的な移動度 $)$, キャリ ア密度 $n_{(\mathrm{ITO}+\mathrm{AZO})} \quad(\mathrm{ITO}+\mathrm{AZO}$ 積層時の平均的なキャリア密 度) \}, Table 2 にはこの時の膜全体のシート抵抗 $R s$ を示 す.この図より, 基板温度 $200 \sim 220^{\circ} \mathrm{C}$ の時に抵抗率が減少 し, 基板温度 $220^{\circ} \mathrm{C}$ の時に最小抵抗率 $\rho_{\text {(ITO }+\mathrm{AZO})}$ は $2.04 \times$ $10^{-4} \Omega \cdot \mathrm{cm}$ （移動度 $\mu_{(\mathrm{ITO}+\mathrm{AZO})}=34.8 \mathrm{~cm}^{2} / \mathrm{V} \cdot \mathrm{s}$ ，キャリア密 度 $\left.n_{(\mathrm{ITO}+\mathrm{AZO})}=8.82 \times 10^{20} \mathrm{~cm}^{-3}\right)$, シート抵抗 $R s$ は $6.83 \Omega /$ ロであった。 さらに温度を増加させると抵抗率が上昇した.

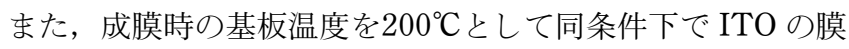
厚を $300 \mathrm{~nm}$ とした膜と ITO + AZO を積層させた膜の電気 的特性とシート抵抗の比較を Table 3 に示す.この結果よ り, ITO + AZO を積層させた膜では ITO 膜と同様の值を得 ることができ，計算上 ITO（インジウム）の使用率を50\% 削減することができた。

次に, $\mathrm{ITO}+\mathrm{AZO}$ 積層透明導電膜と ITO 透明導電膜を自 記分光光度計により測定した透過率スペクトルを Fig. 4 に 示す.この図より，どちらの膜も可視光領域（波長 400 $700 \mathrm{~nm})$ に打ける平均透過率は $80 \%$ 以上を有し, 透明導電 膜として十分機能する值であることがよくわかる．また，

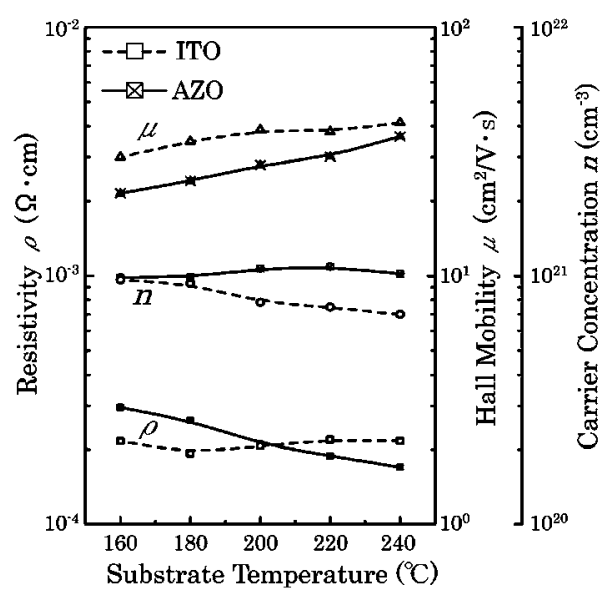

Fig. 2 Electrical properties of ITO films and AZO films at various substrate temperatures.

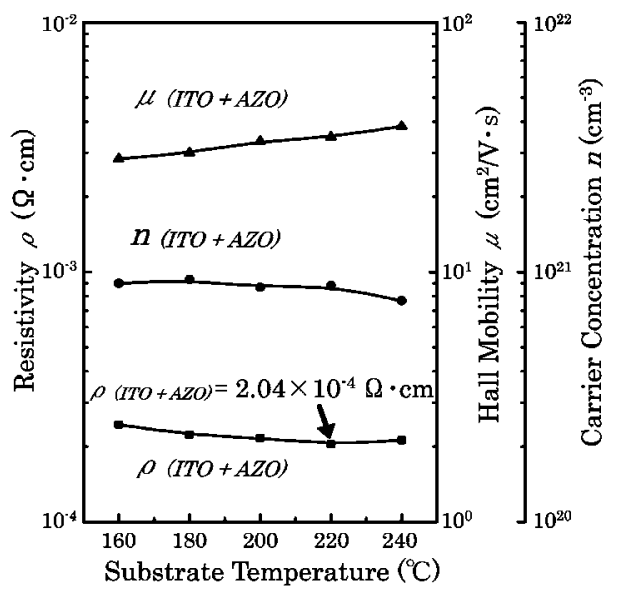

Fig. 3 Electrical properties of $300 \mathrm{~nm}$-thick TCO films with the stacking layer of ITO $(150 \mathrm{~nm})$ and AZO $(150 \mathrm{~nm})$.

Table 2 Sheet resistance of $300 \mathrm{~nm}$-thick TCO films with the stacking layer of ITO and AZO, fabricated at various substrate temperatures

\begin{tabular}{c|l|l|l|l|l}
\hline \hline $\begin{array}{c}\text { Substrate } \\
\text { Temperature } \\
\left({ }^{\circ} \mathrm{C}\right)\end{array}$ & 160 & 180 & 200 & 220 & 240 \\
\hline $\begin{array}{c}\text { Sheet } \\
\text { Resistance } \\
(\Omega / \square)\end{array}$ & 7.81 & 7.32 & 6.86 & 6.83 & 7.63 \\
\hline
\end{tabular}

Table 3 Comparison of electrical properties of $300 \mathrm{~nm}$-thick TCO films with the stacking layer and that of $300 \mathrm{~nm}$-thick ITO films, fabricated at substrate temperature of $200^{\circ} \mathrm{C}$

\begin{tabular}{c|c|c|c|c}
\hline \hline & $\begin{array}{c}\text { Resistivity } \\
(\Omega \cdot \mathrm{cm})\end{array}$ & $\begin{array}{c}\text { Sheet } \\
\text { Resistance } \\
(\Omega / \square)\end{array}$ & $\begin{array}{c}\text { Hall } \\
\text { Mobility } \\
\left(\mathrm{cm}^{2} / \mathrm{V} \cdot \mathrm{s}\right)\end{array}$ & $\begin{array}{c}\text { Carrier } \\
\text { Concentration } \\
\left(\mathrm{cm}^{-3}\right)\end{array}$ \\
\hline ITO & $2.17 \times 10^{-4}$ & 6.88 & 38.6 & $7.47 \times 10^{20}$ \\
\hline ITO+AZO & $2.16 \times 10^{-4}$ & 6.86 & 33.4 & $8.68 \times 10^{20}$ \\
\hline
\end{tabular}

ITO 透明導電膜より ITO + AZO 積層透明導電膜のスペクト ルでは長波長側の透過率が減少している。これはITO+ 


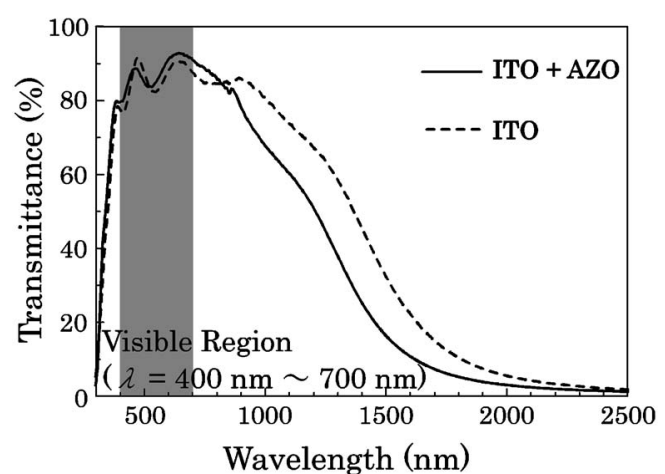

Fig. 4 A comparison of optical properties of $300 \mathrm{~nm}$-thick TCO films with the stacking layer and that of $300 \mathrm{~nm}$-thick ITO films, fabricated at substrate temperature of $200^{\circ} \mathrm{C}$.

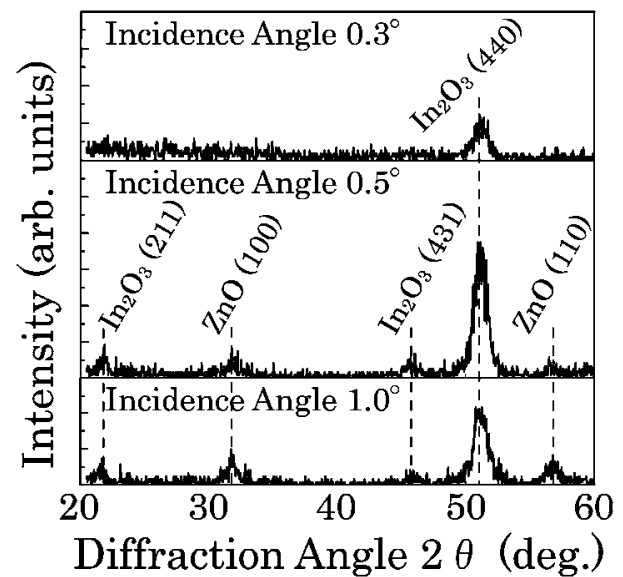

Fig. 5 XRD (In-Plane) spectra of the films with the stacking structure of ITO and AZO.

$\mathrm{AZO}$ 積層透明導電膜のキャリア密度が上昇したことより， 膜中に抢ける自由電子のプラズマ共鳴現象で透過率が減少し たためと考えられる.

次に，X線回折の In-Plane 測定による ITO + AZO 積層透 明導電膜の XRD パターンを Fig. 5 に示す。この図より，X 線の入射角を変えることで, 入射角 $0.3^{\circ}$ の時に $\operatorname{In}_{2} \mathrm{O}_{3}(440)$ 面, 入射角 $0.5^{\circ} \sim 1.0^{\circ}$ の時に $\operatorname{In}_{2} \mathrm{O}_{3}(211)$ 面と $\operatorname{In}_{2} \mathrm{O}_{3}(431)$ 面, $\mathrm{ZnO}(110)$ 面と $\mathrm{ZnO}(100)$ 面が現れた。この結果より，入射 角を深くすることで積層させた膜はITO と AZO が内部で 混合せず，二層に分離して積層していることがわかった。

次に, $\mathrm{ITO}+\mathrm{AZO}$ 積層透明導電膜の表面・断面を $\mathrm{FE}-$ SEM（5 万倍）で観察した結果を Fig. 6 に示す. FE-SEM 像より, ITO + AZO 積層透明導電膜は剥離や空隙もなく, 二層に積層していることが確認できた。これより Fig. 5 の XRD パターンと一致したことがわかった.

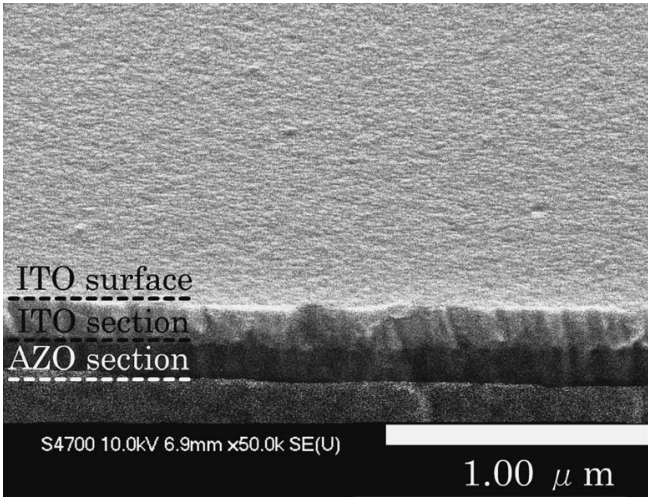

Fig. 6 High-resolution FE-SEM micrographs obtained for the films with the stacking structure of ITO and AZO.

\section{4. ま め}

$\mathrm{ArF}$ エキシマレーザーを用いた PLD 法で ITO + AZO 積 層透明導電膜を作製し，以下の結果を得た.

1）基板温度を変化させて, 合計膜厚 $300 \mathrm{nm（ITO} \mathrm{:} 150$ $\mathrm{nm}, \mathrm{AZO}: 150 \mathrm{~nm}$ ) として積層を行った結果，基板温度 $220^{\circ} \mathrm{C}$ の時に最小抵抗率 $\rho_{(\mathrm{ITO}+\mathrm{AZO})}=2.04 \times 10^{-4} \Omega \cdot \mathrm{cm} （$ 移動 度 $\mu_{(\mathrm{ITO}+\mathrm{AZO})}=34.8 \mathrm{~cm}^{2} / \mathrm{V} \cdot \mathrm{s}$, キャリア密度 $n_{(\mathrm{ITO}+\mathrm{AZO})}=$ $\left.8.82 \times 10^{20} \mathrm{~cm}^{-3}\right)$, シート抵抗 $R_{s}=6.83 \Omega / \square の$ 值を得た.

2) 膜厚 $300 \mathrm{~nm}$ とした ITO 透明導電膜と合計膜厚 300 $\mathrm{nm}$ とした $\mathrm{ITO}+\mathrm{AZO}$ 積層透明導電膜を比較すると, 抵抗 率とシート抵抗は同じ值を得ることができ, ITO（インジウ ム）の使用率を50\%削減することができた。

3） XRDの In-Plane 測定結果より，積層させた膜は内部 でITO とAZO が混合せず，二層に積層していることがわ かった。また，FE-SEM 像で膜断面を観察したところ，二 層に積層していることが確認できた.

\section{謝辞}

本研究を進めるにあたり, 株式会社リガクの太田弘道氏に は X 線回折の In-Plane 測定を行っていただき，ここに感謝 の意を称します.

\section{〔文献〕}

1) F. O. Adurodija, H. Izumi, T. Ishihara, H. Yoshioka, H. Matsui and M. Motoyama: Jpn. J. Appl. Phys., 38 (1999) 2710.

2）鈴木晶雄, 守 昭人, 坂本 淳, 青木孝憲, 松下辰彦, 奥田昌 宏 : 真空, 45 巻 3 号 (2002) 243.

3）南内 嗣 : 応用物理, 75巻10号 (2006) 1218.

4）安倉秀明, 沖中広和, 青木孝憲, 鈴木晶雄, 松下辰彦, 奥田昌 宏 : 真空, 48巻 3 号 (2005) 172 .

5）高瀬康則, 安倉秀明, 中村篤宏, 東村佳則, 鈴木晶雄, 青木孝 憲, 松下辰彦，奥田昌宏 : 真空, 49巻 3 号 (2006) 153.

6）安倉秀明, 高瀬康則, 中村篤宏, 東村佳則, 鈴木晶雄, 青木孝 憲，松下辰彦，奥田昌宏：真空，49巻 9 号（2006） 562.

7) C. H. Yi, I. Yasui and Y. Shigesato: Jpn. J. Appl. Phys., 34 (1995) 1638. 